\title{
Safety Among Newly Resettled Refugees in the USA
}

\author{
Stacey A. Shaw ${ }^{1} \cdot$ Graeme Rodgers $^{2} \cdot$ Patrick Poulin $^{2} \cdot$ Olive Minor $^{2}$ • \\ Ashley Allen ${ }^{1}$
}

Accepted: 22 September 2020/Published online: 3 October 2020

(C) Springer Nature B.V. 2020

\begin{abstract}
Within a context of changing political and social perspectives toward refugee resettlement in the USA, this mixed methods study examines experiences of safety among recently resettled refugees. The study was conducted by resettlement agency personnel within two states, Utah and Arizona. We examine risk and protective factors associated with perceptions of safety among a sample of 243 participants, as well as experiences related to safety as described in focus groups with 50 participants. Of the environmental factors examined, attending events related to one's culture, language, or religion and more frequent home visits were associated with higher levels of perceived safety, while experiencing discrimination was associated with lower levels of perceived safety. Some individual and social factors such as nation of origin were also associated with perceptions of safety. Focus groups identified key themes related to safety in the USA which included discrimination, concerns about family safety, and feeling safe in the USA. An increased emphasis on safety as a key resettlement outcome can strengthen resettlement policy and guide community responses.
\end{abstract}

Keywords Refugee $\cdot$ Resettlement $\cdot$ Safety $\cdot$ USA $\cdot$ Immigration $\cdot$ Forced migration

\section{Introduction}

Opportunities for asylum and resettlement have declined worldwide in recent years as countries that have traditionally provided resettlement opportunities experience increases in nationalism and anti-immigrant sentiment (Connor and Krogstad 2018; Konle-Seidl 2018; European Parliament 2019). Refugee resettlement within the USA is a legal opportunity for permanent residence and citizenship, with case management

Stacey A. Shaw

stacey_shaw@byu.edu

1 School of Social Work, Brigham Young University, Provo, UT, USA

2 International Rescue Committee, New York, NY, USA 
and supports provided during the initial years post-arrival (Bureau of Population, Refugees, and Migration 2020; Darrow 2015; Halpern 2008; U.S. Department of State 2020). The election of Donald Trump to the US Presidency led to a rapid and significant change in the US resettlement program (Darrow and Scholl 2020). Starting in January 2017, the Trump administration utilized executive orders to issue the first of several travel bans (National Conference of State Legislatures 2019). In FY18, the administration lowered the admissions ceiling to 45,000 and narrowed admissions requirements. While the US resettlement program accepted an average of 80,000 people per year from 1980 through 2017 (Kerwin 2018), in fiscal year 2019, the admissions ceiling was lowered to 18,000 (The White House 2019), and only 12,320 people were admitted (Refugee Processing Center 2020). In 2020, admissions will likely be lower due to the COVID-19 pandemic as well as ongoing political restrictions (Refugee Council USA 2020).

The chilling effects of this rapid transformation in the US resettlement program on refugee communities are unknown; however, there may be impacts on refugees' sense of safety and belonging. This study utilized mixed methods to examine perceptions of safety among 243 refugees who resettled to the USA in the latter half of 2016. We examined factors associated with safety through a quantitative assessment as well as through personal experiences related to safety as described in focus groups. This study offers a limited window into how refugees experienced life during increasingly unwelcoming conditions and what this means for their sense of safety.

\section{Literature Review}

Research that examines refugee experiences of safety has focused both on contexts of displacement and permanent resettlement settings. The experience of becoming a refugee is rooted in the well-founded fear of persecution, which drives people from their homes in search of safety (Davenport et al. 2003; Rutinwa 2017; UNHCR 2018). After leaving one's home, perceptions of safety are shaped by the surrounding environment as well as the ongoing effects of pre-migration experiences (Stathopoulou et al. 2019). For the majority of the world's refugees, who are caught up in protracted refugee situations (Loescher and Milner 2005), the ongoing elusiveness of a durable solution may instill a profound fear regarding the future (Stewart and Mulvey 2014). Despite the hardships and insecurities of life in refugee camp and other impermanent settings, refugees endure these, when considered against the serious risks to safety, including death, if they return to their country of origin (Goodman et al. 2015). This literature points to the centrality of safety as an integral aspect of the refugee experience. Escape from violence and persecution does not imply that refugees achieve a sense of safety. Among refugees temporarily residing in a camp in Greece, for example, over half of participants felt unsafe (Stathopoulou et al. 2019). In resettlement contexts, new challenges to safety may emerge. For example, after receiving asylum in England, refugees expressed ongoing fears of harassment and discrimination (Phillimore 2011).

Other studies have further examined factors that influence safety with regard to individual characteristics as well as to environmental contexts (Allik and Kearns 2017). In refugee camp settings, safety varied by national origin, gender, age, economic insecurity, intergenerational conflict, and access to medical services (Bermudez et al. 
2018; Rasmussen and Annan 2010; Stathopoulou et al. 2019). Post-resettlement factors that influence notions of risk and insecurity may be shaped in different ways. Refugees from the Soviet Union who were resettled in Kentucky, for example, expressed higher feelings of safety when compared with the local non-refugee population (Furr et al. 2005). These findings may be attributed to refugee community proximity, resettlement with family members, and access to services (Furr et al. 2005). A longitudinal study among people permanently resettled in Colorado found that from 2011 through 20152016, participants experienced an increase in safety and security each year (Lichtenstein and Puma 2019), suggesting feelings of safety may change over time, as people become more socially connected and knowledgeable regarding their new environment. Among non-refugee populations, safety was associated with race, income, age, city size (Newport 2017), housing, neighborhood quality (Austin et al. 2002), social cohesion, satisfaction with services, and perceived empowerment (Allik and Kearns 2017). These studies suggest that safety is influenced by a range of individual, social, and environmental factors for both refugee and non-refugee communities. Based on this research, we incorporated the ecological model to conceptualize the environmental, individual, and social factors that may influence safety (Allik and Kearns 2017; Bronfenbrenner 1994).

This article also considers how experiences of safety amongst refugees resettled to the USA may be shaped by the integration process as well as community attitudes regarding refugees. We draw on theories of refugee integration alongside research regarding community attitudes and perceptions. Integration theory notes the dual nature of integration, which involves adjustment of newly resettled refugees as well as the responsiveness of host communities (Puma et al. 2018; Strang and Ager 2010). As most theoretical work on integration emphasizes individual adaptation, we also reference literature describing the influence of the far-right anti-immigrant political agenda.

Within refugee studies, many conceptualize safety as a critical aspect of integration. Research with refugee communities in the UK delineated safety in terms of threats by others, tolerance, and welcome by host communities as factors that influenced and defined integration (Ager and Strang 2004). Ager and Strang's (2008) conceptual framework of integration examined safety and stability as one of ten domains, with safety designated as a facilitator of integration, along with language and cultural knowledge (Ager and Strang 2008; Strang and Ager 2010). Drawing from this framework, Puma et al. (2018) developed this notion of safety further, to consider feelings of safety at home as well as outside the home, comfort levels with calling on police or the fire department, trust of neighbors, and experiences of being a victim of crime or discrimination (Puma et al. 2018). They found that 90 days after arrival, feelings of safety were correlated with other aspects of integration, particularly language and social bonding (Puma et al. 2018). Their study identifies community engagement and social connection as critical aspects of adaptation to a new environment. While experiences of safety are viewed as a component of overall adjustment, they do not highlight safety as a central outcome of interest on its own right.

Studies of anti-immigrant sentiment among receiving communities identify biases that may affect refugee safety. Far-right parties in the USA, Europe, and Australia promote narratives regarding the threats posted by immigrants (Hogan and Haltinner 2015). Perceived threats related to economics (employment competition and public benefit usage), culture (social division and a loss of power among white communities), 
and security (terrorism, crime, and disease) (Hogan and Haltinner 2015). Although the data do not support these claims that refugees post a safety risk (Amuedo-Dorantes et al. 2018; Masterson and Yasenov 2019; Sakib and Ishraque Osman 2019), perceptions of refugees and immigrants constituting a threat (Hogan and Haltinner 2015) may foster discrimination, rejection, and fear. Refugee groups with minority racial status face additional challenges to inclusion in countries with entrenched histories of racial bias (Baak 2019). Promulgated beliefs that refugees pose threats likely influence refugees' perception of safety and security in their new communities.

This study utilizes mixed methods to examine a quantitative assessment of safety as well as qualitative experiences with safety among newly resettled refugees in two states (Utah and Arizona) who arrived just prior to the election of Donald Trump as the US President. In this study, safety is defined as subjective individual perceptions regarding safety in three locations: the home, neighborhood, and outside the neighborhood. We utilize the ecological framework (Bronfenbrenner 1994; Sabri et al. 2018) to examine factors associated with safety, incorporating attention to individual refugee experiences with adaptation to life in the USA during a time of increasing hostility and anti-immigrant policies. We conceptualize a range of factors as related to risk and protection, in line with previous research examining associations between safety and risk. Environmental factors examined related to community engagement and reception, with specific measures assessing event attendance, discrimination, comfort calling the police, and frequency of service access (Allik and Kearns 2017; Austin et al. 2002; Bermudez et al. 2018; Lichtenstein and Puma 2019; Newport 2017; Stathopoulou et al. 2019). Individual and social factors assessed included gender, age, nationality, marital status, household size, state, time in the USA, and employment (Furr et al. 2005; Newport 2017; Rasmussen and Annan 2010; Stathopoulou et al. 2019).

We hypothesized that environmental factors were associated with perceptions of safety. First, we hypothesized perceived safety was associated with attending events, service access, and comfort calling the police. Second, we hypothesized lower levels of perceived safety were associated with experiencing discrimination. The qualitative component of the study complements quantitative findings, providing examples of challenges and opportunities in the USA that influence perceptions of safety. We examined safety as an aspect of adaptation and integration, guided by the research question: How is adjustment to life in the USA influenced by participant perceptions of safety?

\section{Methods}

This study was conducted with the International Rescue Committee (IRC), one of nine non-profit voluntary agencies designated to conduct refugee resettlement in the USA. Part of a longitudinal project examining experiences with adjustment and case management, this analysis examines the initial assessment conducted in the first year after arrival. All study procedures were reviewed by the Institutional Review Board at the International Rescue Committee, with a reciprocal approval granted by Brigham Young University. 


\section{Sample}

To be eligible, participants arrived in the USA as a refugee to either the Salt Lake City, Utah, or the Tucson, Arizona, IRC offices. These two locations were selected as they have similar political and cultural climates alongside some differences in long-term agency service provision. In both locations, multiple resettlement agencies have provided services to newcomers for many years. Additionally, the case composition and national backgrounds of clients have traditionally been similar in these sites. Participants were aged 18 years of age or older, with the cognitive ability to provide informed consent. Adults who arrived between the months of June and December of 2016 were invited to participate. A total of 243 unique participants completed an assessment. The assessment was conducted in March through September of 2017.

Participation in the project was voluntary, and all individuals provided informed consent prior to enrollment. Potential participants were informed that their decision would not affect service access or available benefits. Nine individuals declined to participate in the project due to limited time. Bilingual researchers verbally translated English-language consent forms and assessment guides into the language of participant's choice, including Swahili, French, Lingala, Burmese, Farsi, Arabic, Tigrinya, Kinyarwanda, and Nepali. Interviews were conducted by caseworkers as well as other IRC staff, including interns and interpreters who were trained to administer the survey. Assessments were conducted in person, primarily in the participant's home or at the agency office in a private location. Participants were not required to answer questions. Data were collected on tablets designated for use in this project, with information entered in English. Initial assessments were completed in Open Data Kit (ODK) software, after which the team utilized Qualtrics.

In addition to quantitative assessments, 50 people from the sample of 243 participated in focus groups. Focus groups were designed to provide more in-depth understanding of people's experiences with adjustment and services in the US post-resettlement. These groups were stratified by language and gender, focusing on Arabic and Swahili speakers separately by gender in each state, for a total of 8 focus groups. In total, 24 women and 26 men participated in the 8 focus groups. Participants received a $\$ 10$ USD gift card for completing the assessment and \$10 for participating in a focus group, which took an average of $1 \mathrm{~h}$. Completion of the assessment took approximately $45 \mathrm{~min}$.

\section{Measures}

In developing the assessment, we referenced the IRC's outcomes and evidence framework as well as other research conducted with refugee communities (International Rescue Committee 2016; Puma et al. 2018; Shaw and Poulin 2015). We sought to measure a range of individual, social, and community dynamics that may be impacted by service access and may change over time.

To measure safety, participants were asked three questions regarding safety in different locations, including: "How safe do you feel when you are in your home?" "How safe do you feel when walking in your neighborhood?" and "How safe do you feel when you are outside your neighborhood?" For each of these questions, answers included "very safe," "safe," "neither safe nor unsafe," "unsafe," or "very unsafe." For 
bivariate comparison purposes, responses were combined into either "safe" or "unsafe," with the "very unsafe" and "neither safe nor unsafe" response being included with "unsafe." For the multivariate regression models, responses were combined into three categories, including "safe $=2$," "neither safe nor unsafe $=1$," and "unsafe $=0$."

Environmental factors included attending events from one's own and from other cultures; experiences of discrimination; comfort calling the police; and frequency of resettlement agency home visits. Attending events from one's own culture was assessed through asking, "How often do you attend events associated with your culture, language, or religion?" Attending events of another culture was assessed by, "How often have you attended a celebration or event of a culture, ethnic group, language, or religion different from your own?" For both questions, responses included, "At least once a week," "at least once a month," and "only occasionally," which were combined to signify "yes" regarding participation, and "never," which signified "no" participation in events. To measure experience of discrimination, participants were asked, "Since coming to the U.S., how often have you been the victim of racial, cultural, or religious discrimination?" Responses regarding discrimination included "never," "occasionally," and "frequently." Participants were also asked, "Are you comfortable calling the police on your own, if you need to?" in which possible responses included yes or no. To measure interaction with service providers, we asked, "How many times did you personally meet with an IRC staff member at your home?" Over the course of the assessment, this question was modified to asking how many times you met with staff in the last month. Responses were standardized separately for those who completed the assessment before and after the modification and then combined into one variable to allow comparison of how each participant's reported level of interaction varied from the mean.

Individual and social characteristics measured included gender, age, national origin, marital status, household size, time since arrival, state, and employment. National origin included Afghanistan, Bhutan, Burma, Burundi, Cameroon, Central African Republic, Chad, Democratic Republic of Congo, Eritrea, Ethiopia, Iraq, North Korea, Pakistan, Republic of South Sudan, Somalia, Syria, Uganda, and "other." For this analyses, countries of origin included Democratic Republic of Congo (DRC), Bhutan, Burma, Burundi, Syria, Somalia, Iraq, and all others. The most common country of origin, DRC, was used as the comparison group for the multivariate analysis. For marital status, due to a small number of responses, being divorced or widowed was combined with unmarried. When reporting household size, participants were asked, "How many people currently live in your household, including yourself?" To calculate the time since arrival, we calculated the number of days between the date of the interview and the date of arrival. State was determined by research personnel. Employment status was assessed through asking, "Are you currently working?"

The eight focus groups were open ended, with researchers asking about experiences of case management services, general experiences of adjustment post-resettlement, and aspirations for the future. Specific questions included, "What has been the most difficult challenge for you in adjusting to life in the U.S.?" and "What has been a positive part of settling in the U.S.?" 


\section{Data analysis}

Bivariate analyses were conducted to compare environmental as well as individual and social factors by site and by perceptions of safety, with chi-square and $t$ tests used to

Table 1 Bivariate relationships between state, safety, and multi-level factors

\begin{tabular}{|c|c|c|c|}
\hline & Overall $(N=243)$ & Salt Lake City, Utah (140) & Tucson, Arizona (103) \\
\hline \multicolumn{4}{|l|}{ Safety } \\
\hline Unsafe in home & $13(5.3)$ & $6(4.3)$ & $7(6.8)$ \\
\hline Unsafe in neighborhood & $19(7.8)$ & $12(8.6)$ & $7(6.8)$ \\
\hline Unsafe outside of neighborhood ${ }^{1}$ & $30(12.5)$ & $15(10.8)$ & $15(14.9)$ \\
\hline Unsafe combined ${ }^{2}$ & $44(18.3)$ & $26(18.7)$ & $18(17.6)$ \\
\hline \multicolumn{4}{|l|}{ Environmental factors } \\
\hline Events own culture: ${ }^{3}$ Yes & $153(67.7)$ & $92(66.2)$ & $61(70.1)$ \\
\hline No & $73(32.3)$ & $47(33.8)$ & $26(29.9)$ \\
\hline Events other culture: ${ }^{2}$ Yes & $96(39.8)$ & $57(40.7)$ & 39 (38.6) \\
\hline No & $145(60.2)$ & $83(59.3)$ & $62(61.4)$ \\
\hline Discrimination: Experienced & $9(3.7)$ & $7(5.0)$ & $2(1.9)$ \\
\hline Not experienced & $234(96.3)$ & $133(95.0)$ & $101(98.1)$ \\
\hline Calling police: ${ }^{4}$ Comfortable & $209(87.8)$ & $117(85.4)$ & $92(91.1)$ \\
\hline Not comfortable & $29(12.2)$ & $20(14.6)$ & $9(8.9)$ \\
\hline Home visit frequency: M (SD) & & $\mathrm{z}:-.23(.57)^{* *}$ & $.31(1.3)^{* *}$ \\
\hline \multicolumn{4}{|l|}{ Individual and social factors } \\
\hline Gender: ${ }^{5}$ Female, $N(\%)$ & $123(51.0)$ & $69(50.0)$ & $54(52.4)$ \\
\hline Male & $118(49.0)$ & $69(50.0)$ & 49 (47.6) \\
\hline Age: ${ }^{5} \mathrm{M}(\mathrm{SD})$ & $36.8(12.0)$ & $36.7(12.8)$ & $37.0(10.9)$ \\
\hline Nationality: 5 DRC, $N(\%)$ & $61(25.3)$ & $22(15.9)^{* *}$ & $39(37.9)^{* *}$ \\
\hline Syria & $34(14.1)$ & $6(4.3)^{* *}$ & $28(27.2)^{* *}$ \\
\hline Iraq & $28(11.6)$ & $20(14.5)$ & $8(7.8)$ \\
\hline Somalia & 28 (11.6) & $21(15.2)^{*}$ & $7(6.8)^{*}$ \\
\hline Burundi & $14(5.8)$ & $6(4.3)$ & $8(7.8)$ \\
\hline Bhutan & $24(10.0)$ & $20(14.5)^{* *}$ & $4(3.9)^{* *}$ \\
\hline Burma & $11(4.6)$ & $10(7.2)^{*}$ & $1(1.0)^{*}$ \\
\hline Other & $41(17.0)$ & $33(23.9)^{* *}$ & $8(7.8)^{* *}$ \\
\hline Marital status: ${ }^{5}$ Married, $N(\%)$ & $171(71.0)$ & $93(67.4)$ & $78(75.7)$ \\
\hline Unmarried & $70(29.0)$ & $45(32.6)$ & $25(24.3)$ \\
\hline Household size: ${ }^{5} \mathrm{M}(\mathrm{SD})$ & $4.6(2.3)$ & $4.3(2.4)^{*}$ & $5.0(2.1)^{*}$ \\
\hline Time since arrival: ${ }^{5} \mathrm{M}(\mathrm{SD})$ & $279(71)$ & $280(54)$ & $277(88)$ \\
\hline Employed $^{6}$ & $146(60.3)$ & $94(67.1)^{*}$ & $52(51.0)^{*}$ \\
\hline Not employed & $96(39.7)$ & $46(32.9)^{*}$ & $50(49.0)^{*}$ \\
\hline
\end{tabular}

$* p<.05, * * p<.01$

${ }^{1} n=240,{ }^{2} n=200,{ }^{3} n=226,{ }^{4} n=238,{ }^{5} n=241,{ }^{6} n=242$ 
test significance. Available data for each variable assessed is indicated in Tables 1 and 2. Analyses utilized all available data.

A probit regression model with multivariate outcomes was estimated to examine the effects of environmental factors on the three safety outcomes while controlling for individual and social factors. Bayesian estimation was used due to the relatively small sample (Van de Schoot et al. 2015). Bayesian estimation treats the uncertainty of each unknown parameter as a probability distribution (Van de Schoot et al. 2014). Without assumptions about the prior distributions of the structural parameters, no informative priors were specified. The final model fits the data well, as indicated by a high posterior predictive $p$ value of .437. Standardized estimates, 95\% credibility intervals, and significance level are reported in Table 3. Significance of a single tailed test was reported as posterior estimates may not be normally distributed.

Qualitative focus group data were coded line by line, to examine emergent themes from the data. Identified categories, including, "concerns about safety," "harassment and discrimination," and "life in the U.S. is better/safer," were reviewed for inclusion in this paper. We also selected and reviewed any quote mentioning any form of the word "safe." After reviewing these quotes, key themes related to safety were identified.

\section{Results}

Approximately half of the sample was female and participant's average age was 37 . The most common countries of origin included the Democratic Republic of Congo (DRC), Syria, Iraq, and Somalia. The average length of time since arrival was 9 months, with a range from 6 to 16 months. While samples in the two sites did not vary significantly in terms of gender, age, and time since arrival, those in Arizona are more likely to originate from the DRC and Syria, while those in Utah are more likely to be from Somalia, Bhutan, Burma, or other countries (see Table 1). Most participants $(71.0 \%)$ were married and the average household size was 4.6 people. Households were slightly larger on average in Arizona. Most participants (60.3\%) were employed at the time of the survey, with employment higher among participants in Utah.

Most participants (67.7\%) attended events related to their own culture or religion, whereas a smaller number $(39.8 \%)$ attended celebrations or events of a culture, ethnic group, language, or religion different from their own. Some participants $(3.7 \%)$ experienced discrimination. The majority $(87.8 \%)$ felt comfortable calling the police. These environmental factors did not vary significantly by site. The frequency of home visits from agency staff was significantly higher on average in Arizona when compared with Utah.

The majority of participants reported feeling safe in their home, neighborhood, and outside of their neighborhoods. In total, 13 participants $(5.3 \%)$ felt unsafe in their homes, 19 (7.8\%) felt unsafe in their neighborhood, and $30(12.5 \%)$ felt unsafe outside of their neighborhood. In total, 44 participants (18.3\%) felt unsafe in any location. Rates of safety were not significantly different across states.

In the bivariate analysis, a number of environmental and other factors were associated with safety. Regarding environmental factors, participants who attended events related to their own culture, language, or religion were more likely to feel safe within and outside of their neighborhoods. Those who attended events related to other cultures 
Table 2 Bivariate relationships between safety and multi-level factors

\begin{tabular}{|c|c|c|c|c|c|c|}
\hline & \multicolumn{2}{|l|}{ In home } & \multicolumn{2}{|c|}{ In neighborhood } & \multicolumn{2}{|c|}{ Outside neighborhood ${ }^{3}$} \\
\hline & Safe & Unsafe & Safe & Unsafe & Safe & Unsafe \\
\hline \multicolumn{7}{|l|}{ Environmental factors } \\
\hline Events own culture: ${ }^{1}$ Yes & $148(96.7)$ & $5(3.3)$ & $\begin{array}{l}148 \\
(96.7)^{* * *}\end{array}$ & $5(3.3)^{* *}$ & $\begin{array}{l}140 \\
(92.1)^{*}\end{array}$ & $12(7.9)^{*}$ \\
\hline No & $68(93.2)$ & $5(6.8)$ & $62(84.9)^{* * *}$ & $11(15.1)^{* * *}$ & $58(81.7)^{*}$ & $13(18.3)^{*}$ \\
\hline Events other culture: ${ }^{2}$ Yes & $93(96.9)$ & $3(3.1)$ & $90(93.8)$ & $6(6.3)$ & $89(92.7)^{*}$ & $7(7.3)^{*}$ \\
\hline No & $135(93.1)$ & $10(6.9)$ & $132(91.0)$ & $13(9.0)$ & $\begin{array}{l}120 \\
(83.9)^{*}\end{array}$ & $23(16.1)^{*}$ \\
\hline Discrimination: Experienced & $9(100)$ & $0(0)$ & $6(66.7)^{* *}$ & $3(33.3)^{* *}$ & $7(77.8)$ & $2(22.2)$ \\
\hline Not experienced & $224(94.4)$ & $13(5.6)$ & $\begin{array}{l}218 \\
\quad(93.2)^{* *}\end{array}$ & $16(6.8)^{* * *}$ & $203(87.9)$ & $28(12.1)$ \\
\hline Calling police: ${ }^{3}$ Comfortable & $198(94.7)$ & $11(5.3)$ & $194(92.8)$ & $15(7.2)$ & $184(88.5)$ & $24(11.5)$ \\
\hline Not comfortable & $27(93.1)$ & $2(6.9)$ & $15(7.2)$ & $4(13.8)$ & $22(78.6)$ & $6(21.4)$ \\
\hline $\begin{array}{l}\text { Home visit frequency: M } \\
\text { (SD) }\end{array}$ & $\begin{aligned}- & .01 \\
& (1.00)\end{aligned}$ & $.15(.95)$ & $.03(1.03)^{*}$ & $\begin{aligned}- & .33 \\
& (.37)^{*}\end{aligned}$ & $.02(1.03)$ & $-.10(.75)$ \\
\hline \multicolumn{7}{|l|}{ Individual and social factors } \\
\hline Gender: $^{2}$ Female, $N(\%)$ & $116(94.3)$ & $7(5.7)$ & $113(91.9)$ & $10(8.1)$ & $104(86.0)$ & $17(14.0)$ \\
\hline Male & $112(94.9)$ & $6(5.1)$ & $109(92.4)$ & $9(7.6)$ & $104(88.9)$ & $13(11.1)$ \\
\hline Age: ${ }^{2} \mathrm{M}(\mathrm{SD})$ & $36.8(12.2)$ & $37.2(8.4)$ & $37.0(12.1)$ & $34.3(10.6)$ & $36.7(11.6)$ & $38.0(14.4)$ \\
\hline Nationality: ${ }^{2}$ DRC, $N(\%)$ & $59(96.7)$ & $2(3.3)$ & $59(96.7)$ & $2(3.3)$ & $57(95.0)^{*}$ & $3(5.0)^{*}$ \\
\hline Bhutan & $24(100)$ & $0(0)$ & $22(91.7)$ & $2(8.3)$ & $14(58.3)^{* *}$ & $\begin{array}{l}10 \\
(41.7)^{* *}\end{array}$ \\
\hline Burma & $10(90.9)$ & $1(9.1)$ & $10(90.9)$ & $1(9.1)$ & $10(90.9)$ & $1(9.1)$ \\
\hline Burundi & $14(100)$ & $0(0)$ & $13(92.9)$ & $1(7.1)$ & $14(100)$ & $0(0)$ \\
\hline Syria & $29(85.3)^{*}$ & $5(14.7)^{*}$ & $30(88.2)$ & $4(11.8)$ & $22(66.7)^{* *}$ & $11(33.3)^{* *}$ \\
\hline Somalia & $24(85.7)^{*}$ & $4(14.3)^{*}$ & $24(85.7)$ & $4(14.3)$ & $26(92.9)$ & $2(7.1)$ \\
\hline Iraq & $28(100)$ & $0(0)$ & $28(100)$ & $0(0)$ & $28(100)^{*}$ & $0(0)^{*}$ \\
\hline Other & $40(97.6)$ & $1(2.4)$ & $36(87.8)$ & $5(12.2)$ & $37(92.5)$ & $3(7.5)$ \\
\hline $\begin{array}{l}\text { Marital status: }{ }^{2} \text { Married, } N \\
\quad(\%)\end{array}$ & $160(93.6)$ & $11(6.4)$ & $157(91.8)$ & $14(8.2)$ & $145(85.3)$ & $25(14.7)$ \\
\hline Unmarried & $68(97.1)$ & $2(2.9)$ & $65(92.9)$ & $5(7.1)$ & $63(92.6)$ & $5(7.4)$ \\
\hline Household size: ${ }^{2} \mathrm{M}(\mathrm{SD})$ & $4.5(2.3)^{*}$ & $5.5(1.3)^{*}$ & $4.6(2.3)$ & $4.7(2.4)$ & $4.5(2.3)$ & $5.0(1.8)$ \\
\hline State: Utah, $N(\%)$ & $134(95.7)$ & $6(4.3)$ & $128(91.4)$ & $12(8.6)$ & $124(89.2)$ & $15(10.8)$ \\
\hline Arizona & $96(93.2)$ & $7(6.8)$ & $96(93.2)$ & $7(6.8)$ & $86(85.1)$ & $15(14.9)$ \\
\hline Time since arrival: $^{2} \mathrm{M}(\mathrm{SD})$ & $\begin{array}{l}279.8 \\
(71.0)\end{array}$ & $\begin{array}{l}265.1 \\
\quad(63.2)\end{array}$ & $\begin{array}{l}280.3 \\
\quad(71.2)\end{array}$ & $\begin{array}{l}263.4 \\
(61.9)\end{array}$ & $\begin{array}{l}277.5 \\
\quad(69.1)\end{array}$ & $\begin{array}{l}288.1 \\
\quad(82.9)\end{array}$ \\
\hline Employed $^{4}$ & $138(94.5)$ & $8(5.5)$ & $136(92.3)$ & $10(6.8)$ & $\begin{array}{l}132 \\
(91.0)^{*}\end{array}$ & $13(9.0)^{*}$ \\
\hline Not employed & $91(94.8)$ & $5(5.2)$ & 87 (90.6) & $9(9.4)$ & $77(81.0)^{*}$ & $17(18.1)^{*}$ \\
\hline
\end{tabular}

$N=243,{ }^{*} p<.05, * * p<.01,{ }^{1} n=226,{ }^{2} n=241,{ }^{3} n=238,{ }^{4} n=242$ 
Table 3 Multivariate ordinal probit regression model examining the probability safety is associated with environmental factors

\begin{tabular}{|c|c|c|c|c|c|c|c|c|c|}
\hline & \multicolumn{3}{|c|}{ Safe at home } & \multicolumn{3}{|c|}{ Safe in neighborhood } & \multicolumn{3}{|c|}{$\begin{array}{l}\text { Safe outside of } \\
\text { neighborhood }\end{array}$} \\
\hline & Estimate & $\begin{array}{r}p \\
\text { value }\end{array}$ & 95\% C.I. & Estimate & $\begin{array}{r}p \\
\text { value }\end{array}$ & 95\% C.I. & Estimate & $\begin{array}{r}p \\
\text { value }\end{array}$ & 95\% C.I. \\
\hline \multicolumn{10}{|l|}{ Environmental factors } \\
\hline Events own culture & .03 & .36 & $-.15, .23$ & .28 & $.00^{*}$ & $.10, .46$ & .20 & $.01 *$ & $.05, .36$ \\
\hline Events other culture & .19 & .04 & $-.02, .39$ & -.01 & .46 & $-.22, .21$ & .10 & .13 & $-.07, .28$ \\
\hline Discrimination & .07 & .28 & $-.14, .35$ & -.14 & $.01 *$ & $\begin{array}{c}-.25,- \\
.03\end{array}$ & -.06 & .17 & $-.18, .07$ \\
\hline $\begin{array}{l}\text { Comfort calling } \\
\text { police }\end{array}$ & -.04 & .31 & $-.22, .12$ & .04 & .30 & $-.13, .21$ & .12 & .05 & $-.03, .26$ \\
\hline $\begin{array}{l}\text { Home visit } \\
\text { frequency }\end{array}$ & -.05 & .31 & $-.20, .15$ & .40 & $.01 *$ & $.06, .71$ & .19 & $.02 *$ & $.02, .40$ \\
\hline \multicolumn{10}{|c|}{ Individual and social factors } \\
\hline Gender & -.16 & .05 & $-.34, .03$ & -.02 & .44 & $-.22, .19$ & .10 & .12 & $\begin{array}{r}-.07 \\
0.27\end{array}$ \\
\hline Age & -.14 & .09 & $-.35, .07$ & .12 & .15 & $-.10, .36$ & .14 & .05 & $-.03, .32$ \\
\hline \multicolumn{10}{|c|}{ Nationality (DRC: reference) } \\
\hline Syria & -.19 & $.01^{*}$ & $\begin{array}{r}-.36,- \\
.03\end{array}$ & -.01 & .45 & $-.25, .22$ & -.16 & $.02 *$ & $\begin{array}{c}-.32,- \\
.01\end{array}$ \\
\hline Iraq & .22 & .11 & $-.10, .61$ & .37 & .03 & $.00, .73$ & .34 & .03 & $-.02, .71$ \\
\hline Somalia & -.20 & $.02 *$ & $\begin{array}{r}-.37,- \\
.02\end{array}$ & -.13 & .09 & $-.32, .06$ & .05 & .32 & $-.14, .27$ \\
\hline Burundi & .18 & .09 & $-.07, .49$ & -.05 & .30 & $-.23, .16$ & .23 & .06 & $-.04, .59$ \\
\hline Bhutan & .28 & .04 & $-.02, .63$ & -.05 & .32 & $-.27, .18$ & -.34 & $.00^{*}$ & $\begin{array}{c}-.52,- \\
.16\end{array}$ \\
\hline Burma & -.09 & .12 & $-.23, .07$ & -.07 & .22 & $-.24, .11$ & -.05 & .28 & $-.20, .12$ \\
\hline Other & -.04 & .38 & $-.26, .21$ & -.12 & .13 & $-.35, .09$ & -.07 & .28 & $-.27, .16$ \\
\hline Marital status & -.29 & $.01 *$ & $\begin{array}{r}-.52,- \\
.06\end{array}$ & -.10 & .16 & $-.31, .09$ & -.12 & .12 & $-.32, .07$ \\
\hline Household size & -.34 & $.00^{*}$ & $\begin{array}{r}-.55,- \\
.13\end{array}$ & -.10 & .15 & $-.28, .09$ & -.26 & $.00 *$ & $\begin{array}{c}-.44,- \\
.08\end{array}$ \\
\hline Time since arrival & -.08 & .18 & $-.27, .09$ & .03 & .41 & $-.16, .24$ & .10 & .08 & $-.04, .25$ \\
\hline $\begin{array}{l}\text { State (Arizona: } \\
\text { reference) }\end{array}$ & -.10 & .21 & $-.33, .13$ & -.04 & .39 & $-.30, .21$ & .10 & .18 & $-.10, .31$ \\
\hline Employed & -.23 & $.01^{*}$ & $\begin{array}{r}-.45,- \\
.03\end{array}$ & .13 & .13 & $-.11, .33$ & .06 & .24 & $-11, .23$ \\
\hline
\end{tabular}

$N=220$, Standardized results are presented. *One-tailed $p$ value significant at $p<.025$

were also more likely to feel safe outside of their neighborhoods. Additionally, people who experienced discrimination were less likely to feel safe in their neighborhoods. Participants who received home visits more frequently are more likely to feel safe in their neighborhoods (see Table 2). 
Regarding individual and social factors, rates of safety did not vary significantly by gender or age. However, nationality was associated with safety in the home and outside one's neighborhood. People from Syria were less likely to feel safe in their home and outside their neighborhoods when compared with all other participants. Participants from Somalia were also less likely to feel safe in their homes, and those from Bhutan were less likely to feel safe outside their neighborhoods. Alternately, those from the DRC and Iraq were more likely than those from other countries to feel safe outside their neighborhoods when compared with other participants. Examining social factors, those with larger households were less likely to feel safe in their homes, and people who were employed were more likely to feel safe outside of their neighborhoods than those who were not employed.

Multivariate models were used to assess study hypotheses regarding associations between safety and environmental factors. In support of hypothesis 1 that perceived safety was associated with environmental protective factors, attending events related to one's own culture and receiving home visits more frequently were associated with a higher probability of feeling safe within and outside of one's neighborhood. Attending events related to another culture and comfort calling the police were not significantly associated with safety. In support of hypothesis 2 that lower levels of perceived safety were associated with environmental risk, experiencing discrimination is associated with lower levels of perceived safety in the neighborhood (see Table 3).

In addition to environmental factors, some individual and social factors were associated with perceptions of safety. People originating from Syria had a lower probability of feeling safe in their homes and outside their neighborhoods when compared with the reference group (DRC). Additionally, those who originated from Somalia had a lower probability of feeling safe in their homes, and those from Bhutan had a lower probability of feeling safe outside their neighborhoods, when compared with those from the DRC. Both being married and being employed were associated with a lower probability of feeling safe in the home, and larger household size was associated with a lower probability of feeling safe in one's home and outside of one's neighborhood.

\section{Qualitative findings}

The following themes regarding safety emerged from the focus group discussions: (1) persecution related to being different, (2) concerns about family safety, and (3) an overall feeling of safety in the USA.

In relation to being different from other people in the USA, participants described at times being taken advantage of or attacked verbally. For example, a Swahili speaker described:

What I have experienced is [that] it is other people here in United States, they are not right. They are bad people, and most of the American people they are good, but the others they, like as they see a new people came, and they see your English is not good at all, they can wish to do something bad to you.

Some mentioned specific incidents where someone had stolen money, refused owed payment, or treated them poorly. For example, a Swahili speaker described through a 
translator an incident that happened while at work the day prior, where a customer was upset by her accent:

She's working for the airport ... and [the] customer came, and the customer didn't answer. And after that she asked the question 'what can I do for you?', he started insulting her. 'We don't need any [expletive] English in the U.S.A, we need, we need good English, you have to do your best in good English.'

The participant went on to say she could refer the customer to a manager, but otherwise such abuse could not be stopped. Another participant in Tucson described unexplained job loss, "We don't know if it's discrimination because we are Black, or it's a problem of language." After describing the scenario in more detail, the participant described feeling targeted by the former employer, saying "I was thinking perhaps they are happy when they will kick us out with our children and they will be happy to see us living on the streets." This quote illustrates a felt sense of hostility or anger from persons who treated refugees unfairly. Other participants recognized racism as problematic across employment and housing contexts. As one participant stated, "There is discrimination because we are Black. Even where I'm living." Across these scenarios, participants indicated frustration due to inabilities to defend or protect themselves or their family from mistreatment. In some cases uncertain regarding the motives for mistreatment, participants also recognized the influence of racism and a lack of tolerance for Englishlanguage learners or those with certain types of accented English.

Participants also described fears they experienced on behalf of family members. An Arabic speaker described, "I just want to be placed in a community where I can make sure that my family is safe because I work the night shift and when I leave I want to make sure that my family is safe in the place that they live." Additionally, a Swahili speaker described concerns related to becoming homeless, "We are thinking one day they will throw us out because we will not have enough money to pay the rent and we are afraid of where we will go with our children. I'm very afraid and very sad." Some participants were also worried about having their children taken away, as another woman in the same group described:

When we left [the] refugee camp coming here, we were thinking, now we will get home. It's our home in America. But I was surprised, we are living in a house; we can't go outside. If children are going outside police can take them and you lose your children. Even a goat [has] a right to go around, to be free [laughs]. We are living in the house with children, because we are afraid they can take our children.

When asked whether she had heard of children being removed, the participant further reported, "Even my neighbors are very afraid if children are going outside, police is taking." Similarly, a few participants described concerns related to limited English skills and how this may put them and their family members at risk. One participant described, "that's all I think about when I go to work. If something were to happen, they won't, they don't speak the language, so how are they going to ask for help?" Also related to help-seeking and service access, another female participant said, "sometimes we sign papers, [and] we don't know what it is, and we get scared. We came here to 
feel safe, but it's the opposite." These examples indicate the importance of accessibility, including the ability to communicate, in establishing feelings of safety.

In contrast with these fears and difficulties, some participants expressed feeling safe in the USA and described this as central to their post-resettlement experience. A Swahili speaker described, "about the safety, you know, [you] can't compare the two [prior to resettlement]. Here if anything happens if anything goes wrong you have access to 911, you can dial 911 and they'll respond to you." Additionally, an Arabic speaking participant described, through an interpreter:

No discrimination, that's the [thing he] most he likes about [the] United States. The Arab countries they've been to, they can tell who's a refugee and who is not because of a lot of things happening to the refugees. In the United States they don't feel like [they are] refugees, they feel like they're one of, from the same country, just like everybody else.

Later in the same discussion, a participant described, "We don't know about the whole America, but here in Utah, we never felt there's any problem," after which another participant added "what I like the most about [being] here is safety and security, we feel much safer here." These themes of general feelings of safety and concerns about being unsafe in specific contexts were observed across sites, gender, and language. Overall, focus group findings indicated that while many participants feel safe in the USA, there were concerns about keeping children and family members safe, as well as exploitative or abusive incidents.

\section{Discussion}

A number of environmental and other factors influenced perceptions of safety among individuals adjusting to life in the US post-resettlement. Findings highlight the value of the ecological model in recognizing multiple environmental, social, and individual factors that influence safety contexts (Allik and Kearns 2017; Bronfenbrenner 1994; Sabri et al. 2018). Comparing the three safety outcomes measured, participants were most likely to feel safe in their homes and least likely to feel safe in the community. Environmental factors were more often associated with safety at the neighborhood level or outside the neighborhood, not in the home. Additionally, qualitative findings highlight the contrast between relative feelings of safety in the USA and fears specific to environmental contexts. People recognize and value the absence of war and political persecution but have concerns about local policies that may affect family members as well as discriminatory responses from other residents.

In support of the hypotheses that environmental risk and protective factors were associated with safety, participating in events related to one's own culture, home visit frequency, and experiencing discrimination was significantly associated with perceptions of safety. Participation in events associated with one's own culture, language, or religion provides opportunities for social connection and community engagement. Events related to one's culture or religion may be particularly accessible and meaningful. Opportunities for people to be with those who have shared language, cultural, or religious characteristics may enhance safety through providing spaces where people 
experience the familiar, feel understood, and establish or maintain community networks. Research among refugee communities in the USA and elsewhere has identified the value of community engagement in promoting cultural safety, well-being, and belonging (Im and Rosenberg 2016; Riggs et al. 2017). Alternately, participation in cultural events may be more likely among individuals who feel an enhanced sense of safety due to having increased resources such as time, wealth, or social connections that enable community participation. The protective influence of more frequent home visits points to the value of resettlement services provided within the community, where newcomers can discuss concerns and where connections are formed with service providers. Though some focus group participants appreciated the ability to call 911 and trusted police would respond, others expressed fears of the police, including fears that their children would be taken away. The significance of discrimination as a risk factor indicates the negative impact community hostility has on refugee safety and security. Focus group participants identified language-related discrimination and concerns regarding accessing services, particularly emergency services, in their language. Participants described fears of persecution and examples of harassment, though others felt discrimination was not a major concern in the USA. Some examples of persecution, such as anger due to language difference, align with anti-immigrant attitudes that identify difference as a threat (Hogan and Haltinner 2015). These negative encounters pose barriers to safety, where people feel rejected and unwelcome.

Individual and social characteristics also influenced experiences of safety. The finding that those from Syria, Bhutan, and Somalia felt less safe than those from the DRC aligns with differences by country of origin and ethnicity identified in other research (Stathopoulou et al. 2019). These differences could be related to treatment toward those from their country of origin, ethnicity, or religion, as well as to ethnic community size and other characteristics (Furr et al. 2005; Vukovich 2016). Pre- and post-migration experiences that vary by country of origin may influence how people perceive safety. For example, past traumas may sensitize individuals to triggers in the new environment. The risks associated with being married, employed, and having a larger household may relate to family stressors and responsibilities. Focus group participants stressed concerns about the safety of their family members, particularly when they were separated, such as when one parent was working, or when children were outside the home.

Findings build on theoretical work regarding integration and the influence of antiimmigrant perspectives in countries of resettlement such as the USA. As identified in earlier work, safety was tied to adjustment experiences (Ager and Strang 2004; Puma et al. 2018; Strang and Ager 2010). However, this study highlights the centrality of safety as an outcome of interest, rather than conceptualizing safety as one component among many that influence integration. As safety motivates people to resettle and remains a central priority post-resettlement, this outcome may be more salient and relevant to refugee communities and broader US communities than more ambiguous factors such as integration. Safety is particularly relevant in times of growing antagonism toward immigrants (Hogan and Haltinner 2015), when the aim of finding safety may not be realized in places experiencing increases in discrimination and violence. While focus group participants suggested that relative safety in the USA is being achieved by some, further attention to how safety is shaped by racism, xenophobia, and other biases is needed. 
Study findings have implications for US resettlement policy and practice. Rather than the goal of economic self-sufficiency that has governed US resettlement policy since 1980 (Halpern 2008; ORR 2017), or the more recent focus on U.S. border security (Kerwin 2012; U.S. Department of State 2020), an emphasis on measuring and promoting refugee safety would re-align resettlement priorities to serve individuals and families who seek resettlement with this aim. The influence of environmental factors on safety demonstrates the need for communities to build opportunities for fostering support and understanding, both for newcomers and for residents who may be antagonistic toward refugees. Space for interaction and engagement with people from different backgrounds may lead to reductions in biases and fears, increasing safety for refugees as well as non-refugees (Ghosn et al. 2019; Steinmayr 2016). When relationships with social institutions such as the police or child protective services are influenced by fear, additional work on the part of these institutions is needed to address racial and cultural biases, build supportive community relationships, and ensure access to information and resources that enhances individual and family safety. Languagespecific services and access to interpreters are critical, in addition to time and resources for learning English. Resettlement agencies can assist in identifying family and community challenges through engagement and home visits. In addition to assisting newcomers to adapt, resettlement agencies and refugee community organizations can raise awareness regarding culturally and linguistically accessible approaches among other service institutions and the broader community. Organizations, events, and resources that are created by and for refugee communities may be particularly helpful in fostering community understanding and safety. Additional resources that support refugee communities, and research on their role in enhancing safety, are needed.

\section{Limitations}

A number of considerations related to measurement and study processes limit study findings. Findings reflect the experiences of a sample of refugees in two states in the western region of the USA and have limited generalizability to refugees who arrive at different times or who reside in different locations. Dynamics related to location such as state and local policies, cultural and religious climate, crime, anti-immigrant efforts, employment opportunities, and resource availability likely influence experiences with safety and vary across the USA. Additional community and other factors likely influence safety and were not measured or included in these models. Though differences in safety across countries of origin were identified, we were not able to identify how experiences with safety varied based on race or religion. Focus group questions examined adjustment experiences overall and did not assess people's perspectives on safety in different locations. Furthermore, we did not examine specific aspects of violence or fear such as conflict within the family (Sabri et al. 2018). Although participants were assured that being in the study was voluntary and there were no correct answers, implementation of the study by agency personnel may have influenced participation and responses. Additionally, consent forms and instruments were not translated into all participant languages. Although interpreters were instructed on how to ensure participants understood the study and the consent process, as well as how to interpret the assessment, there may have been errors or inconsistency in survey administration. Measuring the quantity of agency services was difficult, and questions 
regarding the frequency of home visits changed during the study to more accurately capture recent participant experience. To mitigate this issue, we standardized the values, but further inquiry into how to measure service quantity and quality is needed.

\section{Conclusions}

This study assessed a diverse sample of people who came to the USA as refugees with an innovative and in-depth examination of an understudied but critical resettlement outcome: safety. Within the context of changing political and social perspectives toward refugee resettlement (Kerwin 2018), most participants felt safe in the USA across home, neighborhood, and community settings. Within this sample, environmental protective factors highlight the value of attending events connected to one's culture, language, or religion as well as receiving home visits from resettlement agency personnel. Discrimination was a risk factor for feeling less safe, with examples of persecution, poor treatment, and fear pointing to the difficulties of achieving security post-resettlement. Additional factors associated with safety point to complexity of safety experiences and the need for additional research on this important outcome.

The need to be safe and ensure family safety is a primary driver of displacement. In examining durable solutions for forced migrants, safety is an important consideration. Alongside economic self-sufficiency, US resettlement programming and research can emphasize and measure safety over time among refugees post-resettlement. In addition to reaching the most central of human needs, this focus coincides with the reason why resettlement programming exists. Focusing on safety can help practitioners identify ways to improve services as a function of ensuring basic needs are being met and can motivate expanded resettlement opportunities as a way to respond to the fear and vulnerability experienced by millions of displaced people worldwide. Future research should examine changes in safety over time, and in different contexts among larger samples, to identify additional factors that influence safety and security in countries of permanent resettlement and asylum.

Acknowledgments We appreciate funding received from the International Rescue Committee for the implementation of this project.

\section{References}

Ager, A., \& Strang, A. (2004). The experience of integration: A qualitative study of refugee integration in the local communities of Pollockshaws and Islington. Research Development and Statistics Directorate, Home Office.

Ager, A., \& Strang, A. (2008). Understanding integration: A conceptual framework. Journal of Refugee Studies, 21(2), 166-191.

Allik, M., \& Kearns, A. (2017). "There goes the fear": feelings of safety at home and in the neighborhood: The role of personal, social, and service factors. Journal of Community Psychology, 45(4), 543-563.

Amuedo-Dorantes, C., Bansak, C., \& Pozo, S. (2018). Refugee admissions and public safety: Are refugee settlement areas more prone to crime?, IZA Discussion Papers, No. 11612. Bonn: Institute of Labor Economics (IZA). 
Austin, D. M., Furr, L. A., \& Spine, M. (2002). The effects of neighborhood conditions on perceptions of safety. Journal of Criminal Justice, 30(5), 417-427.

Baak, M. (2019). Racism and othering for South Sudanese heritage students in Australian schools: Is inclusion possible? International Journal of Inclusive Education, 23(2), 125-141.

Bermudez, L. G., Parks, L., Meyer, S. R., Muhorakeye, L., \& Stark, L. (2018). Safety, trust, and disclosure: A qualitative examination of violence against refugee adolescents in Kiziba Camp, Rwanda. Social Science \& Medicine, 200, 83-91.

Bronfenbrenner, U. (1994). Ecological models of human development. International Encyclopedia of Education, 3(2), 37-43.

Bureau of Population, Refugees, and Migration. (2020). Reception and placement. U.S. Department of State. https://www.state.gov/refugee-admissions/reception-and-placement/ Accessed 8 July 2020.

Connor, P. \& Krogstad, J. M.. (2018). The number of refugees admitted to the U.S. has fallen, especially among Muslims. Pew Research Center. http:/www.pewresearch.org/fact-tank/2018/05/03/the-numberof-refugees-admitted-to-the-u-s-has-fallen-especially-among-muslims/ Accessed 12 September 2019.

Darrow, J. H. (2015). Getting refugees to work: A street-level perspective of refugee resettlement policy. Refugee Survey Quarterly, 34(2), 78-106.

Darrow, J. H., \& Scholl, J. H. (2020). Chaos and confusion: Impacts of the Trump administration executive orders on the US refugee resettlement system. Human Service Organizations: Management, Leadership \& Governance, 1-19.

Davenport, C., Moore, W., \& Poe, S. (2003). Sometimes you just have to leave: Domestic threats and forced migration, 1964-1989. International Interactions, 29(1), 27-55.

European Parliament (2019). Asylum and migration in the EU: Facts and figures. https:/www.europarl. europa.eu/news/en/headlines/society/20170629STO78630/ Accessed 12 September 2019.

Furr, L. A., Austin, D. M., Cribbs, S. E., \& Smoger, S. H. (2005). The effects of neighborhood satisfaction on perception of safety among refugees from the former Soviet Union. Sociological Spectrum, 25(5), 593617.

Ghosn, F., Braithwaite, A., \& Chu, T. S. (2019). Violence, displacement, contact, and attitudes toward hosting refugees. Journal of Peace Research, 56(1), 118-133.

Goodman, S., Burke, S., Liebling, H., \& Zasada, D. (2015). 'I can't go back because if I go back I would die': How asylum seekers manage talk about returning home by highlighting the importance of safety. Journal of Community \& Applied Social Psychology, 25(4), 327-339.

Halpern, P. (2008). Refugee economic self-sufficiency: An exploratory study of approaches used in office of refugee resettlement programs. US Department of Health and Human Services. http://citeseerx.ist.psu. edu/viewdoc/download?doi=10.1.1.473.1584\&rep=rep1\&type=pdf Accessed 8 July 2020.

Hogan, J., \& Haltinner, K. (2015). Floods, invaders, and parasites: Immigration threat narratives and rightwing populism in the USA, UK and Australia. Journal of Intercultural Studies, 36(5), 520-543.

Im, H., \& Rosenberg, R. (2016). Building social capital through a peer-led community health workshop: A pilot with the Bhutanese refugee community. Journal of Community Health, 41(3), 509-517.

International Rescue Committee. (2016). Welcome to the outcomes and evidence framework. http://oef. rescue.org/\#/?_k=wq7vbl. Accessed 20 July 2020.

Kerwin, D. (2012). The faltering US refugee protection system: Legal and policy responses to refugees, asylum-seekers, and others in need of protection. Refugee Survey Quarterly, 31(1), 1-33.

Kerwin. (2018). The US refugee resettlement program-A return to first principles: How refugees help to define, strengthen, and revitalize the United States. Journal on Migration and Human Security, 6(3), 205225.

Konle-Seidl, R. (2018). Integration of refugees in Austria, Germany and Sweden: Comparative analysis. European Parliament. http:/www.europarl.europa.eu/RegData/etudes/STUD/2018/614200/IPOL_ STU(2018)614200_EN.pdf Accessed 12 September 2019.

Lichtenstein, G., \& Puma, J. E. (2019). The refugee integration survey and evaluation (RISE): Results from a four-year longitudinal study. Journal of Refugee Studies, 32(3), 397-416.

Loescher, G., \& Milner, J. H. (2005). Protracted refugee situations: Domestic and international security implications (Vol. 375). Taylor \& Francis.

Masterson, D., \& Yasenov, V. (2019). Does halting refugee resettlement reduce crime? Evidence from the United States refugee ban. IZA Discussion Paper No. 12551. https://ssrn.com/abstract=3445817 Accessed 10 July 2020.

National Conference of State Legislatures. (2019). Federal travel ban: Trump administration actions limiting noncitizen travel to the U.S. and courts. http://www.ncsl.org/research/immigration/federal-travel-ban. aspx. Accessed 19 September 2019. 
Newport, F. (2017). Americans' fear of walking alone ties 52-year low. Gallup. https://news.gallup.com/poll/ 221183/americans-fear-walking-alone-ties-year-low.aspx Accessed 30 June 2020.

Office of Refugee Resettlement. (2017) Annual Report to Congress. Fiscal Year 2015. Administration for Children \& Families, U.S. Department of Health \& Human Services. https:/www.acf.hhs.gov/sites/ default/files/orr/arc_15 final_508.pdf Accessed 8 July 2020.

Phillimore, J. (2011). Refugees, acculturation strategies, stress and integration. Journal of Social Policy, 40(3), $575-593$.

Puma, J. E., Lichtenstein, G., \& Stein, P. (2018). The rise survey: Developing and implementing a valid and reliable quantitative measure of refugee integration in the United States. Journal of Refugee Studies, 31(4), 605-625.

Rasmussen, A., \& Annan, J. (2010). Predicting stress related to basic needs and safety in Darfur refugee camps: A structural and social ecological analysis. Journal of Refugee Studies, 23(1), 23-40.

Refugee Council USA. (2020). Refugee Arrivals. https://rcusa.org/refugee-arrivals/ Accessed 25 June 2020.

Refugee Processing Center. (2020). FY2019 arrivals by region. https://www.wrapsnet.org/archives/ Accessed 25 June 2020.

Riggs, E., Muyeen, S., Brown, S., Dawson, W., Petschel, P., Tardiff, W., et al. (2017). Cultural safety and belonging for refugee background women attending group pregnancy care: An Australian qualitative study. Birth, 44(2), 145-152.

Rutinwa, B. (2017). The end of asylum? The changing nature of refugee policies in Africa. In International Refugee Law (pp. 35-64). Routledge.

Sabri, B., Nnawulezi, N., Njie-Carr, V. P., Messing, J., Ward-Lasher, A., Alvarez, C., \& Campbell, J. C. (2018). Multilevel risk and protective factors for intimate partner violence among African, Asian, and Latina immigrant and refugee women: Perceptions of effective safety planning interventions. Race and Social Problems, 10(4), 348-365.

Sakib, N., \& Ishraque Osman, S. M. (2019). Syrian refugee influx and the rise of far-right rhetoric: A quasiexperimental investigation. European Politics and Society, 1-13.

Shaw, S. A., \& Poulin, P. (2015). Findings from an extended case management US refugee resettlement program. Journal of International Migration and Integration, 16(4), 1099-1120.

Stathopoulou, T., Avrami, L., Kostaki, A., Cavounidis, J., \& Eikemo, T. A. (2019). Safety, health and trauma among newly arrived refugees in Greece. Journal of Refugee Studies, 32(Special Issue 1), i22-i35.

Steinmayr, A. (2016). Exposure to refugees and voting for the far-right:(unexpected) results from Austria. IZA Discussion Paper No. 9790 https://ssrn.com/abstract=2750273 Accessed 10 July 2020.

Stewart, E., \& Mulvey, G. (2014). Seeking safety beyond refuge: the impact of immigration and citizenship policy upon refugees in the UK. Journal of Ethnic and Migration Studies, 40(7), 1023-1039.

Strang, A., \& Ager, A. (2010). Refugee integration: Emerging trends and remaining agendas. Journal of Refugee Studies, 23(4), 589-607.

The White House. (2019). Presidential determination on refugee admissions for fiscal year 2020. https:// www.whitehouse.gov/presidential-actions/presidential-determination-refugee-admissions-fiscal-year2020/ Accessed 19 July 2020.

U.S. Department Of State. (2020). Report to congress on proposed refugee admissions for FY2020. https:// www.state.gov/reports/report-to-congress-on-proposed-refugee-admissions-for-fy- 2020/ Accessed 8 July 2020.

UNHCR. (2018). Refugees. http://www.unhcr.org/en-us/refugees.html Accessed 12 September 2019.

Van de Schoot, R., Kaplan, D., Denissen, J., Asendorpf, J. B., Neyer, F. J., \& van Aken, M. A. G. (2014). A gentle introduction to Bayesian analysis: Applications to developmental research. Child Development, 85(3), 842-860.

Van de Schoot, R., Broere, J. J., Perryck, K. H., Zondervan-Zwijnenburg, M., \& van Loey, N. E. (2015). Analyzing small data sets using Bayesian estimation: The case of posttraumatic stress symptoms following mechanical ventilation in burn survivors. European Journal of Psychotraumatology, 6.

Vukovich, M. M. (2016). Exploring ethnocultural differences in distress of newly arrived refugees during early resettlement: A mixed methods dissertation. https://digitalcommons.du.edu/etd/1196/ Accessed 12 September 2019.

Publisher's Note Springer Nature remains neutral with regard to jurisdictional claims in published maps and institutional affiliations. 